\title{
Range extensions for heterobranch sea slugs (formerly opisthobranch) belonging to the families Diaphanidae, Plakobranchidae and Facelinidae on the eastern coast of Australia - CORRIGENDUM
}

\author{
MATT J. NIMBS, RICHARD C. WILLAN AND STEPHEN D.A. SMITH
}

doi: 10.1017/S1755267215000524, Published by Cambridge Journals Online, 20 May 2015.

Keywords: climate change, Colpodaspis thompsoni, Elysia pusilla, Phidiana bourailli, Herviella claror, corrigendum

In this paper an image of an undetermined Bosellia sp. (Plakobranchidae) from Sandy Beach (= Low Reef) was inadvertently published in Fig. 2(B) rather than an image of an Elysia pusilla as intended. Despite the incorrect published image, the record of E. pusilla from Sandy Beach remains correct. A replacement image of E. pusilla from Sandy Beach is provided herewith.

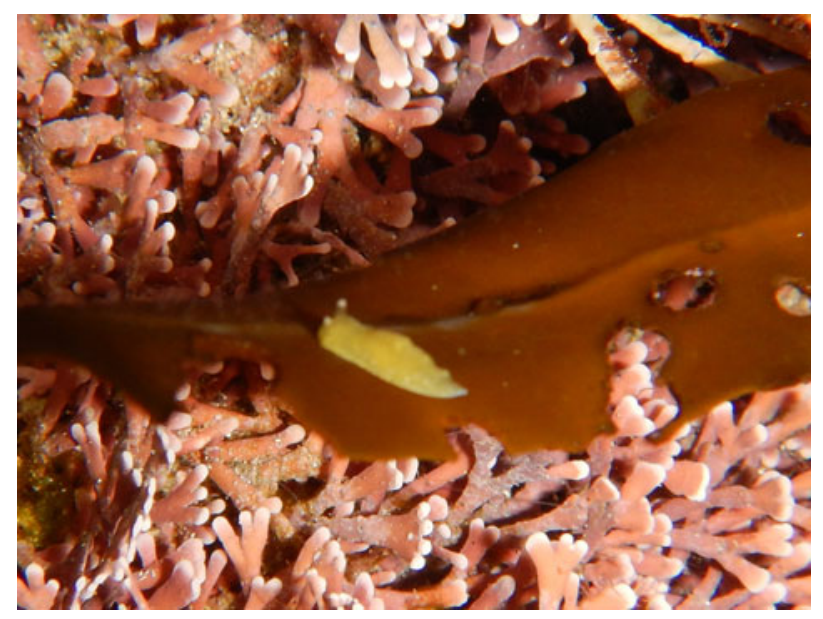

Fig. 2(B).

REFERENCE

Nimbs M.J., Willan R.C. \& Smith S.D.A. (2015) Range extensions for heterobranch sea slugs (formerly opisthobranch) belonging to the families Diaphanidae, Plakobranchidae and Facelinidae on the eastern coast of Australia. Marine Biodiversity Records 8, (e76), 1-6, doi: 10.1017/ S1755267215000524. 